\title{
FREQÜÊNCIA DE INDIVÍDUOS COM ANTICORPOS SERICOS ANTI-CYSTICERCUS CELLULOSAE EM CINCO MUNICÍPIOS DO ESTADO DE SÃO PAULO
}

\section{Adelaide José Vaz, Antonio Shigueo Guskuma Hanashiro, Pedro Paulo Chieffi e Antonio Walter Ferreira}

\begin{abstract}
Considerando a importância da cisticercose humana em Saúde Pública, foi estudada a freqüencia de positividade da detecção de anticorpos anti-Cysticercus cellulosae em 1.264 amostras de soro, assim distribuídas: Grupo I-1.064 de indivíduos da população geral ( 821 adultos e 243 crianfas) residentes em cinco municipios do Estado de Säo Paulo (São Paulo, Presidente Prudente, Santos, Campinas e Marília). Brasil; Grupo II-200 de pacientes adultos internados em hospital psiquiátrico (Presidente Prudente). Para a pesquisa dos anticorpos séricos foi empregado o teste ELISA utilizando como suporte discos de tecido-resina. No Grupo I foram encontrados $19(2,30 \%)$ sóros reagentes entre as amostras de adultos, e $2(0,82 \%)$ entre as das crianças; entre os doentes psiquiátricos, Grupo II, a freqüência de positividade foi de $5 \%$, significativamente maior $(p<0,05)$ do que a encontrada para os adultos do Grupo $I$.
\end{abstract}

Palavras-chaves: Cisticercose humana. Cysticercus cellulosae. Anticorpos séricos anti-Cysticercus cellulosae. Teste imunoenzimático ELISA.

A cisticercose humana representa importante problema de Saúde Pública nos paises em desenvolvimento, pela elevada incidência, pela gravidade dos quadros clínicos e pela precariedade de recursos terapêuticos específicos 91011 . A letalidade da forma neurológica ainda é elevada, e acredita-se que o número de casos assintomáticos, não submetidos a critérios diagnósticos especificos, também seja elevado 810 .

A prevalência atual e real da cisticercose humana, em particular da neurocisticercose, é de dificil avaliação, já que os dados existentes referem-se aos casos-doença e são restritos, na maioria das vezes, a Centros especializados de Neurologia 810.

No presente estudo a proposta foi avaliar a freqüência de individuos com anticorpos séricos antiCysticercus cellulosae em população humana geral residente em cinco municípios do Estado de São Paulo (São Paulo, Presidente Prudente, Santos, Campinas e Marília), e em população internada em hospital psiquiátrico (Presidente Prudente).

\footnotetext{
Seçāo de Sorologia, Serviço de Microbiologia e Imunologia, Instituto Adolfo Lutz.

Faculdade de Ciências Médicas da Santa Casa de São Paulo. Instituto de Medicina Tropical de São Paulo.

Endereço para correspondência: Dra. Adelaide José Vaz. Instituto Adolfo Lutz. Av. Dr. Arnaldo 355, 01246 São Paulo, SP, Brasil.

Recebido para publicação em 22/02/90.
}

\section{MATERIAL E MÉTODOS}

1. População estudada: foram obtidos 1.264 soros de indivíduos residentes em cinco municípios do Estado de São Paulo, assim distribuidos:

Grupo I. 1.064 de indivíduos da população geral, sendo 821 adultos, 492 do sexo feminino 329 do sexo masculino, com idade entre 16 e 78 anos (33,3 $\pm 12,4$ anos), 281 residentes em São Paulo, 191 em Presidente Prudente, 145 em Santos, 133 em Campinas e 71 em Marilia; e 243 crianças, 124 do sexo feminino e 119 do sexo masculino, com idade entre um e 15 anos (7,5 $\pm 3,6$ anos), 102 residentes em Santos, 76 em São Paulo e 65 em Campinas.

Este grupo de amostras de soro foi escolhido ao acaso dentre as amostras encaminhadas ao Laboratório Central do Instituto Adolfo Lutz, para a realização de testes diagnósticos de sifilis. Todas as amostras foram não-reagentes no teste VDRL.

Grupo II. 200 amostras de pacientes do sexo masculino, idade entre 15 e 64 anos (37,4 $\pm 13,1$ anos), internados no Hospital Psiquiátrico Bezerra de Menezes em Presidente Prudente.

2. Teste imunoenzimático ELISA: foi empregado o teste ELISA com componentes antigênicos de Cysticercus cellulosae quimicamente ligados a discos de poliéster sobre os quais foi polimerizada resina de $\mathrm{N}$-metilol-acrilamida, conforme metodologia descrita por Vaz e Ferreira13. 
Vaz AJ, Hanashiro ASG, Chieffi PP, Ferreira AW. Freqüência de individuos com anticorpos séricos anti-Cysticercus cellulosae em cinco Municipios do Estado de São Paulo. Revista da Sociedade Brasileira de Medicina Tropical 23:97-99, abr-jun, 1990

3. Estudo estatístico: foram calculadas as frequêencias de positividade do teste ELISA para os dois grupos estudados. As diferenças observadas foram analisadas quanto a sua significância pelo teste do Qui-quadrado ${ }^{6}$.

\section{RESULTADOS}

Os resultados obtidos são apresentados na Tabela 1. Utilizando-se como "cut off" do teste ELISA, o titulo imediatamente inferior a 2,20 (1:160), observou-se positividade em $19(2,30 \%)$ dos 821 soros de adultos e em $2(0,82 \%)$ dos 243 soros de crianças do Grupo I; e em $10(5,00 \%)$ dos 200 soros do Grupo II, pacientes adultos internados com distúrbios psiquiátricos. A freqüência de positividade obtida neste último grupo foi significativamente maior $(p<0,05)$ do que a observada para os adultos do Grupo I.

Tabela 1 - Distribuicão dos titulos obtidos no teste ELISA para deteção de anticorpos anti-Cysticercus cellulosae nos soros de 821 adultos e 243 criancas da população geral e de 200 pacientes adultos psiquiátricos.

\begin{tabular}{|c|c|c|c|c|}
\hline \multirow{2}{*}{$\begin{array}{l}\text { Grupo } \\
\text { Populacional }\end{array}$} & \multicolumn{3}{|c|}{ Título no teste ELISA* (\%) } & \multirow[b]{2}{*}{ Total } \\
\hline & $<2,20$ & 2,20 a 2,49 & $\geq 2,50$ & \\
\hline \multicolumn{5}{|l|}{ I. Geral } \\
\hline Adultos & $802(97,70)$ & $8(0,97)$ & $11(1,33)$ & 821 \\
\hline Crianças & $241(99,18)$ & - & $2(0,82)$ & 243 \\
\hline $\begin{array}{l}\text { II. Hospital } \\
\text { psiquiátrico }\end{array}$ & $190(95,00)$ & $3(1,50)$ & $7(3,50)$ & 200 \\
\hline
\end{tabular}

*log da diluição do soro.

Dos 21 soros reagentes pertencentes ao Grupo I, população geral, dois eram de crianças, uma menina residente em Santos $(1 / 102=0,98 \%)$ e um menino residente em São Paulo $(1 / 76=1,32 \%)$. Dos 19 adultos soros-reagentes, 6 eram do sexo masculino, representando $1,82 \%$ da população masculina adulta, e 13 eram do sexo feminino, ou $2,64 \%$ do total feminino adulto.

As freqüências de positividade para os adultos do Grupo I por cidade de residência foram: $2,85 \%$ $(n=8)$ de São Paulo; 2,09\% $(n=4)$ de Presidente Prudente; $2,07 \%(n=3)$ de Santos; $2,26 \%(n=3)$ de Campinas e $1,41 \%(n=1)$ de Marilia.

Não foi possivel estabelecer diferenças significativas entre os resultados obtidos para os individuos adultos do Grupo I, com relação ao sexo e cidade do domicílio.

\section{DISCUSSÃO}

O emprego de testes imunológicos em estudos epidemiológicos tem sido pouco descrito para a cisticercose humana. Flisser e cols ${ }^{4}$, em 1976, no México, encontraram $0,49 \%$ de positividade entre 3.226 soros estudados através da imunoeletroforese. No Brasil, Ueda e cols ${ }^{12}$, em 1984 , utilizando a reação de fixação de complemento para cisticercose, encontraram freqüências de reatividade de $0,87 \%$ e $3,80 \%$ em soros, respectivamente, de 824 individuos supostamente normais residentes em Santos e Presidente Prudente, SP, e de 234 pacientes do Hospital Psiquiátrico Bezerra de Menezes (Presidente Prudente). Mais recentemente, Vianna e cols ${ }^{14}$, em 1986 , detectaram anticorpos anti-Cysticercus cellulosae em 5,2\% dos soros de 1.122 individuos residentes em Brasília, DF, utilizando os testes de imunofluorescência indireta $\mathrm{e}$ ELISA.

No presente estudo foram observadas freqüências de positividade de $2,30 \%, 0,82 \%$ e $5,00 \%$, respectivamente para soros de 821 adultos e 243 crianças da população geral e 200 pacientes adultos internados em hospital psiquiátrico, residentes em cinco municípios do Estado de São Paulo. As 200 amostras de pacientes psiquiátricos internados foram obtidas da mesma amostragem estudada previamente por Ueda e cols ${ }^{12}$. A maior sensibilidade do teste ELISA poderia explicar a maior frequêencia de positividade aqui encontrada no mesmo grupo de pacientes.

Não se pode constatar diferença significativa entre as porcentagens de soros reagentes obtidas entre as crianças e os adultos da população geral (Grupo I), embora a freqüência de positividade tenha sido maior entre os adultos, como é esperado para a doença, pelas observações de outros autores 5810 . A freqüência significativamente mais elevada $(p<0,05)$ observada entre os soros dos pacientes psiquiátricos, sugere o maior risco da doença, particularmente da forma neurológica, nesse grupo 111214 .

Ressalta-se que frequências de soro-positividade muito mais elevadas têm sido descritas para pacientes com sintomas neurológicos como epilepsia e hipertensão intracraniana, empregando as reações de hemaglutinação passiva ${ }^{2}$, ELISA $^{3}$ e imunofluorescência indireta ${ }^{7}$.

Em estudos soro-epidemiológicos, o emprego de testes sensiveis, como o teste imunoenzimático ELISA $^{13}$, revela a freqüência de indivíduos com anticorpos anti-Cysticercus cellulosae na população em geral, incluindo os individuos com cisticercose cerebral ou extracerabral, sintomática ou assintomática, individuos que tenham tido contato com o parasita e os falsos-positivos. Apesar de não possibi- 
Vaz AJ, Hanashiro ASG, Chieffi PP, Ferreira AW. Freqüencia de individuos com anticorpos séricos anti-Cysticercus cellulosae em cinco Municípios do Estado de Säo Paulo. Revista da Sociedade Brasileira de Medicina Tropical 23:97-99, abr-jun, 1990

litar o diagnóstico individualizado dos casos de cisticercose, a identificação de indivíduos soro-positivos facilita a localização de microambientes (núcleos familiares ou geográficos) nos quais haja risco de transmissão ${ }^{1}$.

O teste ELISA aqui utilizado é de simples execução e leitura ${ }^{13}$, e os resultados obtidos ressaltam mais uma vez a importância de estudos epidemiológicos sobre a cisticercose humana em nosso meio.

\section{SUMMARY}

Considering the important health public problem that human cysticercosis represents, the frequency of anti-Cysticercus cellulosae antibodies was studied in 1,264 serum samples, 1,064 being from the general population individuals (821 adults and 243 children) living in five municipalities of São Paulo State, Brazil; and 200 from patients admitted to the Psychiatric Hospital Bezerra de Menezes (Presidente Prudente). Discs of synthetic fabric-resin with the Among the sera from adults, nineteen $(2,30 \%)$ were valently bound were employed for ELISA tests. Among the sera from adults, mineteen (2.30\%) were reactive $2(0.82 \%)$ among the childrens sera. Ten (5.00\%) among the psychiatric patients sera presented reactivity. This was significantly higher than that observed for the adults of the general population group $(p<0.05)$.

Key-words: Human cysticercosis. Cysticercus cellulosae. Anti-Cysticercus cellulosae antibodies. ELISA.

\section{AGRADECIMENTOS}

Agradecemos aos funcionários da Biolab Diagnóstica S/A, na pessoa do Dr. Mário E. Camargo, pelo preparo dos discos de tecido-resina.

\section{REFERÊNCIAS BIBLIOGRÁFICAS}

1. Centro Panamericano de Zoonosis. Informe de la reunión técnica sobre normatización y estrategias para la implementación del inmunodiagnóstico de la cisticercosis humana. Organização Panamericana de Saúde. Buenos Aires, 1989.

2. Chopra JS, Kaur U, Mahajan RC. Cysticerciasis and epilepsy: a clinical and serological study. Transactions of the Royal Society of Tropical Medicine and Hygiene 75:518-520, 1981.
3. Diwan AR, Coker-Vann M, Brown P, Subianto DB, Yolken R, Desowitz R, Escobar A, Gibbs Jr CJ, Gajdusek DC. Enzyme-linked immunosorbent assay (ELISA) for the detection of antibody to cysticerci of Taenia solium. The American Journal of Tropical Medicine and Hygiene 31:364-369, 1982.

4. Flisser A, Bulnes I, Diaz ML, Luna R, Woodhouse E, Beltrán F, Martinez I, Larralde C. Estudio seroepidemiológico de la cisticercosis humana en poblaciones predominantemente indigenas y rurales del Estado de Chiapas. Archivos de Investigación Médica 7:107-113, 1976.

5. Gobbi H, Adad SJ, Neves RR, Almeida HO. Ocorrência de cisticercose (Cysticercus cellulosae) em pacientes necropsiados em Uberaba, MG. Revista de Patologia Tropical 9:51-59, 1980.

6. Hoel PG. Estatística Elementar. Atlas. Sảo Paulo, p. 275-291, 1982.

7. Livramento JA. Contribuição de reações de imunofluorescência no líquido cefalorraqueano ao estudo da neurocisticercose. Arquivos de Neuropsiquiatria 39:261$278,1981$.

8. Machado ABB, Pialarissi CSM, Vaz AJ. Cisticercose humana diagnosticada em hospital geral, São Paulo, SP (Brasil). Revista de Saúde Pública 22:240-244, 1988.

9. Mahajan RC. Geographical distribution of human cysticercosis. In: Flisser A (ed) Cysticercosis: present state of knowledge and perspectives. Academic Press, New York, p. 39-46, 1982.

10. Schenone H, Vilarroel F, Rojas A, Ramirez R. Epidemiology of human cysticercosis in Latin America. In: Flisser A (ed) Cysticercosis: present state of knowledge and perspectives. Academic Press, New York, p. 25-38, 1982.

11. Spina-França A. Cisticercose do sistema nervoso central, considerações sobre 50 casos. Revista Paulista de Medicina 48:59-70, 1956.

12. Ueda M, Nakamura PM, Waldman EA, Chieffi PP, Souza AMC, Spir M, Gerbi LJ. Freqüência de anticorpos anti-Cysticercus cellulosae em população de risco para cisticercose e em segmento de populaçāo considerado supostan ente normal, em regiōes do Estado de São Paulo, Brasil. Revista do Instituto Adolfo Lutz 44:25-28, 1984.

13. Vaz AJ, Ferreira AW. Imunodiagnóstico da neurocisticercose: teste imunoenzimático com antígenos quimicamente ligados a suportes para pesquisa de anticorpos em soro e líquido cefalorraquiano. Revista do Instituto de Medicina Tropical de São Paulo 30:1-10, 1988.

14. Vianna LG, Macêdo V, Costa JM, Mello P, Souza D. Estudo soroepidemiológico da cisticercose humana em Brasília, Distrito Federal. Revista da Sociedade Brasileira de Medicina Tropical 19:149-156, 1986. 